\title{
Avaliação Biológica de Linhagem de Soja com Baixa Atividade de Inibidores de Tripsina ${ }^{1}$ \\ Edna Mayumi Yuahasi Miura², Marco Aurélio R. Binotti ${ }^{3}$, Daliane Souza de Camargo 4 , Ivone Yurika Mizubuti ${ }^{5}$, Elza louko Ida ${ }^{6}$
}

\begin{abstract}
RESUMO - Cultivar de soja BR 36 com atividades de inibidores de tripsina convencional e linhagem de soja BRM 95-5262 geneticamente modificadas para conter baixas atividades de inibidores de tripsina foram utilizados em ensaios biológicos com aves contendo 40 e $20 \%$ e 30 e $20 \%$ de atividades residuais relativa de inibidores de tripsina, respectivamente. Os valores médios de PER, NPR e CA indicaram que os tratamentos de soja crua foram inferiores aos tratamentos de soja processados termicamente. Entretanto, tratamentos de soja processados termicamente com inativação de $20 \%$ de atividades residuais relativa de inibidores de tripsina não apresentaram diferenças significativas entre si e em relação ao padrão farelo de soja. Porém, quando as atividades de inibidores de tripsina final foram de 8,61 e 8,44 UIT/mg de amostra ou 20 e 30\% de atividades residuais relativa dos respectivos cultivar BR 36 e linhagem BRM 95-5262, observou-se que os valores médios de PER, NPR e CA não foram significativos. Concluiu-se que os valores de PER, NPR e CA obtidos com a proteína de soja foram dependentes das atividades iniciais de inibidores de tripsina e do seu respectivo tratamento térmico e que há vantagem na utilização da soja BRM 95-5262 com baixas atividades de inibidores de tripsina.
\end{abstract}

Palavras-chave: aves, ensaio biológico, inbidores de tripsina, soja

\section{Biological Evaluation of Soybean Line with low Trypsin Inhibitor Activities}

\begin{abstract}
The soybean meal (raw and thermal processed) from soybean cultivar BR 36 with conventional trypsin inhibitor activities levels (standard) and the soybean line BRM95-5262 that was genetically selected to contain low trypsin inhibitor activities were used in a biological assays with chicks. The BR 36 and BRM95-5262 soybean meal (thermal processed), used in the assays contained, respectively, 40 and 20, and 30 and $20 \%$ of relative residual trypsin inhibitors activities. The mean values of PER, NPR and feed: gain showed that the treatments with raw soybean meals were lower than the treatments with thermal processed soybean meals. However, thermal processed soybean meal treatments with $20 \%$ of relative residual trypsin inhibitor activities did not show significant differences between them and in relation to the standard, soybean meal. However, when the final residual trypsin inhibitor activities were 8.61 and $8.44 \mathrm{UIT} / \mathrm{mg}$ of samples or 20 and $30 \%$ of relative residual trypsin inhibitor activities of the BR 36 cultivar and BRM95-5262 line soybean meal, respectively, it was observed that the mean values of PER, NPR and F: G were not significant. So, the values of PER, NPR and F: G obtained with soybean meal was dependent of initial relative residual trypsin inhibitor activities and of its respective thermal treatments. There was advantage to use the BRM95-5262 soybean meal line with low relative residual trypsin inhibitor activities.
\end{abstract}

Key Words: chicks, biological assays, trypsin inhibitors, soybean

\section{Introdução}

A soja tem sido amplamente utilizada como fonte de óleo comestível e proteína para alimentação humana e animal. A existência da soja é descrita desde 1000 anos antes de Cristo no Japão e na China e, somente a partir do século XIX, passou a ter importância econômica.

O farelo de soja contém cerca de $40 \%$ de proteína e, a partir do desengorduramento, é possível produzir vários subprodutos para consumo hu- mano e animal, como concentrados, isolados e texturizados protéicos (SNYDER e KWON, 1987).

A soja tem sido descrita por conter antinutrientes que limitam a sua utilização. $\mathrm{O}$ mais importante e extensivamente investigado dos antinutrientes protéicos são os inibidores de proteases (PUSZTAI et al., 1991). Estes antinutrientes apresentam especificidade de inibir as enzimas proteolíticas e, conseqüentemente, reduzem a digestão protéica de alimentos, proporcionando diminuição no ganho de peso e crescimento dos animais (LIENER, 1994). Dessa forma, para aumentar

\footnotetext{
${ }^{1}$ Parte da Dissertação de Mestrado apresentado à UEL pela primeira autora, financiada pelo CNPq.

2 Mestre em Ciências de Alimentos. Secretaria de Estado de Agricultura e Abastecimento. E.mail: ednamiurasan@uol.com.br

3 Pós-graduação em Ciências de Alimentos. Universidade Estadual de Londrina (UEL).

${ }^{4}$ Acadêmica do Curso de Medicina Veterinária.

5 Professora doutora. Departamento de Zootecnia - UEL. E.mail: mizubuti54@hotmail.com

6 Professora doutora. Departamento de Tecnologia de Alimentos e Medicamentos - UEL. E.mail: idaelza@sercomtel.com.br
} 
o valor nutricional da soja e seus produtos, há necessidade de processamentos térmicos para inativá-los.

Com finalidade de reduzir custos no processamento de soja e diminuir os teores destes antinutrientes, foram desenvolvidos cultivares de soja com baixo teor de inibidor de tripsina e ausência do inibidor Kunitz. Tem-se também investigado cultivar com ausência do inibidor Bowman-Birk. Cultivares livres desses dois inibidores de tripsina (IT) também têm sido investigados (DOMAGALSKI et al., 1992).

Comercialmente, já existe cultivar de soja com ausência do inibidor Kunitz. Porém, para maximizar seu valor nutricional, seria necessário processamento térmico menos drástico, quando comparado com cultivar de soja com atividades de IT convencional (ANDERSON-HAFERMANN et al., 1992; HERKELMAN et al., 1993), bem como manutenção da qualidade protéica.

O objetivo deste trabalho foi avaliar o efeito de linhagem de soja com baixas atividades de IT sobre alguns parâmetros biológicos em frangos de corte.

\section{Material e Métodos}

\section{Matéria prima e ensaios analíticos}

Foram utilizados cultivar de soja BR36 com atividades de IT convencional e a linhagem BRM 95-5262 com baixa atividade de IT. A linhagem BRM 95-5262 foi proveniente do cruzamento das linhagens Paraná (2) com PI 157440 (com ausência de inibidor de tripsina Kunitz). Estas amostras foram cedidas pela Embrapa-soja (Empresa Brasileira de Pesquisa Agropecuária - Centro Nacional de Soja, Londrina - PR).

A atividade dos inibidores de tripsina (AIT) foi determinada conforme metodologia preconizada por KAKADE et al. (1974), com modificação no processo de extração segundo LIU e MARKAKIS (1989). A determinação de proteína bruta foi de acordo com ASSOCIATION OF OFFICIAL ANALYTICAL CHEMISTS - AOAC (1990).

\section{Processamento térmico}

As amostras de soja foram previamente moídas e desengorduradas. Em seguida, ajustou-se para $16 \%$ de umidade com a adição de água destilada. O processamento térmico foi feito em banho-maria a $95^{\circ} \mathrm{C}$ com fixação da porcentagem de atividade residual relativa de IT (Tabela 1) em 40 e $20 \%$ e 30 e $20 \%$ de atividades residuais relativa de IT para BR $36 \mathrm{e}$ BRM 95-5262, respectivamente.
Tabela 1 - Tempo de retenção, em minutos, do processamento térmico para obtenção das amostras

Table 1 - Retention time in minutes of thermal processing to obtain the samples

\begin{tabular}{lccc}
\hline Soja & Tempo $(\mathrm{min})$ & (UIT/mg) & $\%$ IT $^{1}$ \\
Soybean & Time & AIT & \\
\hline BR36 & 0 & 43,06 & 100 \\
& 43 & 17,22 & 40 \\
& 126 & 8,61 & 20 \\
BRM95-5262 & 0 & 28,15 & 100 \\
& 14 & 8,44 & 30 \\
& 31 & 5,63 & 20 \\
\hline
\end{tabular}

$\overline{1 \% \mathrm{IT}}=$ porcentagem de atividades residuais relativa de IT (percentage of relative residual tripsin inhibitors activities).

Delineamento estatístico e ensaio biológico com aves

O ensaio biológico foi conduzido na Fazenda Escola do Centro de Ciências Agrárias da Universidade Estadual de Londrina. Foram utilizados 240 pintos machos da linhagem Hubbard com sete dias de idade pesando entre 155,33 e 161,33g, distribuídos em boxes.

O delineamento estatístico utilizado foi o inteiramente casualizado com oito tratamentos, três repetições e 10 aves por unidade experimental. Os tratamentos $(\mathrm{T})$ foram: $\mathrm{T} 1=$ aprotéica, $\mathrm{T} 2=$ farelo de soja, $\mathrm{T} 3=$ cultivar BR 36 cru, $\mathrm{T} 4=$ cultivar BR 36 com $40 \%$ da atividade residual relativa de IT, T5 = cultivar BR36 com 20\% da atividade residual relativa de IT, T6 = linhagem BRM 95-5262 cru, T7 = linhagem BRM 95-5262 com 30\% da atividade residual relativa de IT e T8 = linhagem BRM 95-5262 com 20\% da atividade residual relativa de IT. O tratamento 1 (T1) foi realizado apenas para auxiliar na obtenção dos dados de quociente de eficiência líquida da proteína (NPR) dos demais tratamentos.

Para as análises estatísticas, utilizou-se o programa SAS. Foram feitas análises de variâncias e teste Tukey para comparações entre médias.

Inicialmente, a ração pré-teste calculada para conter $23 \%$ de proteína bruta (Tabela 2) foi fornecida durante os primeiros 7 dias de vida. Em seguida, após jejum de uma noite, os pintos foram pesados e alojados aleatoriamente nos diferentes tratamentos.

Com exceção da ração aprotéica, todas as rações experimentais (Tabela 3) foram formuladas para conter $9 \%$ de proteína bruta, conforme recomendações de WILLIS e BAKER (1980). Para atender as exigências nutricionais das aves, todas as rações foram balanceadas para conter $3200 \mathrm{kcal}$ de energia metabolizável (EM) por kg e quantidades suficientes 
1756 Rev. bras. zootec.

Tabela 2 - Composição percentual e calculada da ração pré-teste

Table 2 - Percentage and calculated composition of the pre test diet

\begin{tabular}{|c|c|c|c|c|c|c|}
\hline $\begin{array}{l}\text { Ingredientes } \\
\text { Ingredient }\end{array}$ & $\mathrm{kg}$ & $\begin{array}{l}\text { Proteína bruta }(\%) \\
\text { Crude protein }\end{array}$ & $\begin{array}{l}\mathrm{EM}(\mathrm{kcal} / \mathrm{kg}) \\
M E(\text { kcal } / \mathrm{kg})\end{array}$ & $\mathrm{Ca}(\%)$ & $\operatorname{Pd}(\%)$ & $\begin{array}{l}\text { Metionina (\%) } \\
\text { Methionine }\end{array}$ \\
\hline $\begin{array}{l}\text { Milho moído } \\
\text { Ground corn }\end{array}$ & 46,41 & 3,95 & 1585,00 & 0,009 & 0,042 & 0,078 \\
\hline $\begin{array}{l}\text { Farelo de soja } \\
\text { Soybean meal }\end{array}$ & 41,78 & 19,05 & 953,00 & 0,150 & 0,075 & 0,272 \\
\hline $\begin{array}{l}\text { Calcário } \\
\text { Limestone }\end{array}$ & 1,65 & - & - & 0,61 & - & - \\
\hline $\begin{array}{l}\text { Fosfato bicálcico } \\
\text { Dicalcium phosphate }\end{array}$ & 1,04 & - & - & 0,235 & 0,384 & - \\
\hline $\begin{array}{l}\text { Supl. vitamínico + aditivos }{ }^{1} \\
\text { Vitaminic supl }+ \text { additives }\end{array}$ & 0,60 & - & - & - & - & - \\
\hline $\begin{array}{l}\text { Supl. mineral }{ }^{2} \\
\text { Mineral supl. }\end{array}$ & 0,06 & - & - & - & - & - \\
\hline $\begin{array}{l}\text { Sal } \\
\text { Salt }\end{array}$ & 0,50 & - & - & - & - & - \\
\hline $\begin{array}{l}\text { Colina } \\
\text { Choline }\end{array}$ & 0,20 & - & - & - & - & - \\
\hline $\begin{array}{l}\text { Metionina } \\
\text { Methionine }\end{array}$ & 0,16 & - & - & - & - & 0,15 \\
\hline Óleo vegetal & 7,60 & - & 668,00 & - & - & - \\
\hline
\end{tabular}

1 Suplemento vitamínico contendo por kg do produto: (Vitaminic suplement containing by kg of product): Vit. A, 1.600.000 UI; Vit. D 320.000 UI; Vit. E, $3.600 \mathrm{mg}$; Vit. $\mathrm{K}_{3} 480 \mathrm{mg}$; Vit. $\mathrm{B}_{1}, 320 \mathrm{mg}$; Vit. $\mathrm{B}_{2}, 960 \mathrm{mg}$; Ác. pantotênico (pantotenic acid), $1920 \mathrm{mg}$, Ác. nicotínico (nicotinic acid), $4800 \mathrm{mg}$; Vit. $\mathrm{B}_{6}, 640 \mathrm{mg}$; Acido fólico (folic acid), $160 \mathrm{mg}$; Vit. B ${ }_{12}, 2,40 \mathrm{mg}$; Biotina (biotin), $16 \mathrm{mg}$; Se, $50 \mathrm{mg}$; Colina (coline), $52.000 \mathrm{mg}$; Metionina (met), $352.800 \mathrm{mg}$; Antioxidante (antioxidan), $19.600 \mathrm{mg}$; Coccidiostático (coccidiostat), $12.000 \mathrm{mg}$; Promotor crescimento (growth promoter), $20.000 \mathrm{mg}$; Veículo q.s.p., $1000 \mathrm{~g}$.

2 Suplemento mineral contendo por kg do produto (Mineral suplement containing by kg of product): Mn, 160 g; Fe, 100 g; Cu, 100 g; Co, 20 g; l, 2 g; Veículo q.s.p., $1000 \mathrm{~g}$.

de sais minerais e vitaminas, atendendo as exigências nutricionais das aves conforme recomendações do NATIONAL RESEARCH COUNCIL - NRC (1994). Constam da Tabela 3 a composição percentual das rações experimentais e os valores calculados, que representam os diferentes tratamentos $(\mathrm{T})$.

Água e ração foram fornecidas à vontade durante todo o período experimental de nove dias.

A relação de eficiência protéica (PER) foi determinada conforme o método descrito pela AOAC (1990), com modificação conforme descrito por HAN et al. (1991); o NPR, de acordo com metodologia descrita por WALKER (1983); e a conversão alimentar (CA), pelo quociente consumo de ração e ganho de peso.

\section{Resultados e Discussão}

A relação de eficiência protéica (PER), o quociente de eficiência líquida da proteína (NPR) e a conversão alimentar (CA) foram determinados a partir das médias de ganho de peso e consumo de proteína durante nove dias.

A análise de variância para os valores biológicos de PER, NPR e CA de todos os tratamentos, com exceção do aprotéico (T1), indicou que houve diferenças significativas $(\mathrm{P} \leq 0,05)$ entre os tratamentos.

Os valores médios de PER, NPR e CA dos diferentes tratamentos, avaliados por intermédio do teste Tukey, encontram-se na Tabela 4. Os valores de PER, NPR e CA do padrão farelo de soja diferiram dos tratamentos de soja cruas. Entretanto, os tratamentos de soja processados até $20 \%$ de atividades residuais relativa de IT não diferiram do padrão farelo de soja, indicando, dessa forma, a eficiência do processamento térmico com relação aos valores de PER, NPR e CA. Considerando as atividades de IT final de 8,61 e 8,44 UIT/mg de amostra ou 20 e $30 \%$ de atividades residuais relativa de IT dos respectivos cultivares BR 36 e BRM 95-5262, observou-se que os valores médios de PER, NPR e CA não foram significativos $(\mathrm{P} \geq 0,05)$. Para avaliação do valor biológico da proteína, é importante, também, considerar a concentração inicial de atividade de IT da amostra original, e não as porcentagens de atividades residuais relativas.

Os valores médios de PER de 2,18 e 3,05 dos tratamentos de soja BR 36 e BRM 95-5262 cruas, respectivamente, diferiram entre si $(\mathrm{P} \leq 0,05)$ e do 
MIURA et al.

Tabela 3 - Composição percentual e valores calculados da ração testemunha e das rações experimentais

Table 3 - Percentage composition and calculated values of the control and experimental diets

\begin{tabular}{|c|c|c|c|c|c|c|c|c|}
\hline \multirow[t]{2}{*}{$\begin{array}{l}\text { Ingredientes } \\
\text { Ingredients }\end{array}$} & \multicolumn{8}{|c|}{$\begin{array}{c}\text { Ração experimental } \\
\text { Experimental diet }\end{array}$} \\
\hline & $\mathrm{T} 1$ & $\mathrm{~T} 2$ & $\mathrm{~T} 3$ & $\mathrm{~T} 4$ & $\mathrm{~T} 5$ & T6 & $\mathrm{T} 7$ & $\mathrm{~T} 8$ \\
\hline $\begin{array}{l}\text { Farelo de soja } \\
\text { Soybean meal }\end{array}$ & - & 19,74 & - & - & - & - & - & - \\
\hline BR36 & - & - & 17,61 & 17,61 & 17,61 & - & - & - \\
\hline $\begin{array}{l}\text { BRM95-5262 } \\
\text { Óleo }\end{array}$ & - & $\overline{-}$ & - & - & - & 19,13 & 19,13 & 19,13 \\
\hline $\begin{array}{l}\text { Oil } \\
\text { Fosfato bicálcico } \\
\text { Dicalcium phosphate }\end{array}$ & 2,93 & 2,73 & 2,75 & 2,75 & 2,75 & 2,74 & 2,74 & 2,74 \\
\hline $\begin{array}{l}\text { Calcário } \\
\text { Limestone }\end{array}$ & 0,91 & 0,84 & 0,91 & 0,91 & 0,91 & 0,91 & 0,91 & 0,91 \\
\hline $\begin{array}{l}\text { Metionina } \\
\text { Methionine }\end{array}$ & 0,51 & 0,37 & 0,41 & 0,41 & 0,41 & 0,40 & 0,40 & 0,40 \\
\hline $\begin{array}{l}\text { Colina } \\
\text { Choline }\end{array}$ & 0,20 & 0,20 & 0,20 & 0,20 & 0,20 & 0,20 & 0,20 & 0,20 \\
\hline $\begin{array}{l}\text { Vitaminas }+ \text { aditivos }{ }^{1} \\
\text { Vitamin }+ \text { additive }\end{array}$ & 0,60 & 0,60 & 0,60 & 0,60 & 0,60 & 0,60 & 0,60 & 0,60 \\
\hline $\begin{array}{l}\text { Minerais }{ }^{2} \\
\text { Minerals }\end{array}$ & 0,06 & 0,06 & 0,06 & 0,06 & 0,06 & 0,06 & 0,06 & 0,06 \\
\hline $\begin{array}{l}\text { Amido } \\
\text { Starch }\end{array}$ & 88,28 & 74,26 & 73,40 & 73,40 & 73,40 & 71,19 & 71,19 & 71,19 \\
\hline $\begin{array}{l}\text { Areia } \\
\text { Sand }\end{array}$ & 6,01 & - & 3,56 & 3,56 & 3,56 & 4,27 & 4,27 & 4,27 \\
\hline $\begin{array}{l}\text { Valores calculados } \\
\text { Calculated values }\end{array}$ & & & & & & & & \\
\hline $\begin{array}{l}\text { Proteína bruta }(\%) \\
\text { Crude protein }\end{array}$ & 0,00 & 9,00 & 9,00 & 9,00 & 9,00 & 9,00 & 9,00 & 9,00 \\
\hline $\begin{array}{l}\mathrm{EM}(\mathrm{kcal} / \mathrm{kg}) \\
M E\end{array}$ & 3200 & 3200 & 3200 & 3200 & 3200 & 3200 & 3200 & 3200 \\
\hline $\begin{array}{l}1 \text { Suplemento vitamínico } \\
\text { Vit. E, } 3.600 \mathrm{mg} \text {; Vit. K } \\
4800 \mathrm{mg} ; \text { Vit. B } 6 \text {, } 640 \mathrm{mb} \\
\text { (methionine), } 352.800 \mathrm{mg} \\
20.000 \mathrm{mg} \text {; Veículo q.s } \\
2 \text { Suplemento mineral con } \\
\text { q.s.p., } 1000 \mathrm{~g} \text {. }\end{array}$ & $\begin{array}{l}\text { ntendo p } \\
480 \mathrm{mg} \text {; } \\
\text { ccido fólic } \\
\text { ntioxidan } \\
1000 \mathrm{~g} \text {. } \\
\text { do por kg }\end{array}$ & $\begin{array}{l}\text { do produtc } \\
\text { 1,320 } \mathrm{mg} ; \\
\text { acid), } 160 \mathrm{r} \\
\text { ioxidan), } 19 \\
\text { oduto (Mine }\end{array}$ & $\begin{array}{l}\text { inic suplel } \\
\text {, } 960 \mathrm{mg} \\
\mathrm{B}_{12}, 2,40 \\
\text { g; Coccid } \\
\text { ment cont }\end{array}$ & $\begin{array}{l}\text { pontaining } \\
\text { pantotêni } \\
\text { 3iotina (bic } \\
\text { ico (coccia } \\
\text { by kg of pro }\end{array}$ & $\begin{array}{l}\text { of product } \\
\text { pantotenic } \\
16 \mathrm{mg} ; \mathrm{Se}, \\
\text { t) } 12.000 \mathrm{r} \\
\mathrm{Mn}, 160 \mathrm{~g}\end{array}$ & $\begin{array}{l}\text { A, } 1.600 . \\
1920 \mathrm{mg} \text {, } \\
\text { ig; Colina ( } \\
\text { romotor cr } \\
100 \mathrm{~g} ; \mathrm{Cu},\end{array}$ & $\begin{array}{l}\text { Ul; Vit. } \mathrm{D}_{3} \text {, } \\
\text { nicotínico ( } \\
\text { ) } 52.000 \mathrm{~m} \\
\text { nento (grov } \\
\text {; Co, } 20 \mathrm{~g} \text {; }\end{array}$ & $\begin{array}{l}320.000 \text { UI } \\
\text { icotinic acid) } \\
\text { g; Metionin } \\
\text { th promoter) } \\
2 \mathrm{~g} \text {; Veículc }\end{array}$ \\
\hline
\end{tabular}

controle padrão, sendo superiores aos valores médios de 1,21 para soja convencional e 2,52 para soja com baixas atividades de IT crua descritos por HAN et al. (1991).

Os valores de NPR de 3,85 e 4,32 dos tratamentos de soja BR 36 e BRM 95-5262 crua, respectivamente, diferiram significativamente entre si $(\mathrm{P} \leq 0,05)$ e foram menores quando comparados com o padrão farelo de soja. Entretanto, os resultados encontrados foram superiores àqueles observados por HAN et al.(1991).

Os valores médios de CA dos tratamentos de soja crua diferiram significativamente $(\mathrm{P} \leq 0,05)$ entre si e do padrão. Observa-se que os valores de CA do tratamento BRM 95-5262 crua foram menores que o tratamento BR36 crua. YEN et al. (1973), HAN et al. (1991), ANDERSON-HAFERMANN et al. (1992) e HERKELMAN et al. (1993) também verificaram que os valores de CA de farelos de soja convencio- nais crus e com baixas atividades de IT de amostras cruas foram inferiores às processadas termicamente. Porém, quando comparadas com ambas amostras cruas, a linhagem com baixas atividades de IT apresentou menor valor de CA em relação ao cultivar convencional.

O ganho de peso corporal e o consumo de ração dos animais que receberam tratamentos processados termicamente de até $20 \%$ de atividades residuais de IT aumentaram em relação ao cultivar BR36 convencional crua. Porém, para linhagem BRM95-5262, observou-se apenas aumento significativo $(\mathrm{p} \leq 0,05)$ no ganho de peso corporal com o processamento térmico de até $20 \%$ de atividades residuais relativas de IT. Vários pesquisadores (YEN et al.,1973; NITSAN e NIR,1977; HAN et al., 1991 e HERKELMAN et al., 1993) também observaram que 
Rev. bras. zootec.

Tabela 4 - Valores médios de relação de eficiência protéica (PER), quociente de eficiência líquida protéica (NPR), conversão alimentar (CA), ganho de peso (GP) e consumo de ração (CR) dos diferentes tratamentos

Table 4 - Average values of protein efficiency relationship (PE), quocient of protein net efficiency (PNE), feed: gain ratio (F:C), average weight gain (WG) and feed intake (FI) of the different treatments

\begin{tabular}{llllll}
\hline Tratamento & PER & NPR & CA & GP & CR \\
Treatment & $P E$ & $P N E$ & $F: G$ & $W G$ & $F I$ \\
\hline $\begin{array}{l}\text { Farelo de soja padrão } \\
\text { Soybean meal }\end{array}$ & $3,71^{\mathrm{A}}$ & $4,91^{\mathrm{A}}$ & $2,69^{\mathrm{D}}$ & $95^{\mathrm{A}}$ & $25,53^{\mathrm{A}}$ \\
BR 36 crua & & & & & \\
BR 36 Raw & $2,18^{\mathrm{E}}$ & $3,85^{\mathrm{C}}$ & $4,59^{\mathrm{A}}$ & $39,33^{\mathrm{D}}$ & $18,10^{\mathrm{C}}$ \\
BR 36/40\% IT $^{1}$ & $2,76^{\mathrm{D}}$ & $4,26^{\mathrm{B}}$ & $3,62^{\mathrm{B}}$ & $55,33^{\mathrm{C}}$ & $20,10^{\mathrm{C}}$ \\
BR 36/20\% $\mathrm{IT}^{1}$ & $3,59^{\mathrm{AB}}$ & $4,87^{\mathrm{A}}$ & $2,79^{\mathrm{D}}$ & $85,00^{\mathrm{AB}}$ & $23,70^{\mathrm{AB}}$ \\
BRM 95-5262 crua & $3,05^{\mathrm{CD}}$ & $4,32^{\mathrm{B}}$ & $3,29 \mathrm{C}$ & $72,67^{\mathrm{B}}$ & $23,83^{\mathrm{AB}}$ \\
BRM95-5262 raw & & & & & \\
BRM 95-5262/30\% $\mathrm{IT}^{1}$ & $3,33^{\mathrm{BC}}$ & $4,66^{\mathrm{A}}$ & $3,00^{\mathrm{CD}}$ & $76,00^{\mathrm{B}}$ & $22,80^{\mathrm{B}}$ \\
BRM 95-5262/20\% $\mathrm{IT}^{1}$ & $3,70^{\mathrm{A}}$ & $4,90^{\mathrm{A}}$ & $2,70^{\mathrm{D}}$ & $93,33^{\mathrm{A}}$ & $25,23^{\mathrm{A}}$ \\
CV $(\%)$ & 3,55 & 2,22 & 3,50 & 6,66 & 3,62 \\
\hline
\end{tabular}

Médias, na coluna, seguidas de letras diferentes são significativos $(p<0,05)$ pelo teste de Tukey.

${ }_{1}^{1}$ Porcentagem residual relativa de inibidores de tripsina do respectivo tratamento.

Mean, within a column, followed by different letters are significant $(p<.05)$ by Tukey test.

Percentage of relative residual protein inhibitors of the respective treatment.

houve aumento no ganho de peso e consumo de ração em aves, quandoo farelo de soja foi processado termicamente.

Considerando a atividade de IT inicial do cultivare da linhagem de soja, observa-se na Tabela 4 que o processamento térmico melhorou os valores de PER, NPR, CA e ganho de peso. Os resultados de PER, NPR, CA e ganho de peso indicaram a importância da utilização de linhagem de soja com baixas atividades de IT, devido à redução do tempo de processamento e, possivelmente, à manutenção da qualidade protéica.

\section{Conclusões}

Os valores de relação de eficiência protéica, quociente de eficiência líquida protéica, ganho de peso e conversão alimentar, obtidos com a proteína de soja, foram dependentes das atividades iniciais de inibidores de tripsina e do seu respectivo tratamento térmico.

\section{Referências Bibliográficas}

ANDERSON-HAFERMANN, J.C., ZHANG, Y., PARSONS, C.M. 1992. Effect of heating on nutritional quality of conventional and Kunitz trypsin inhibitor-free soybeans. Poult. Sci.,71:1700 - 1709.

ASSOCIATION OF OFFICIAL ANALYTICAL CHEMISTS AOAC. 1990. Official Methods of Analysis. Kenneth Helrich. Fifteenth edition. Arlington, Virginia. v.2. 1298p.

DOMAGALSKI, J.M., KOLLIPARA,K.P., BATES, A.H. et al. 1992. Nulls for the major soybean Bowman-Birk protease inhibitor in the genus Glycine. Crop Sci., 32:1502-1505.

HAN, Y., PARSONS, C.M., HYMOWITZ,T. 1991. Nutritional evaluation on soybeans varing in trypsin inhibitor content.
Poult. Sci., 70:896-906.

HERKELMAN, K.L., CROMWELL, G.L., CANTOR, A.H. et al. 1993. Effects of heat treatment on the nutritional value of conventional and low trypsin inhibitor soybeans for chicks. Poult. Sci., 72:1359-1369.

KAKADE, M.L., RACKIS, J.J., McGHEE, J.E. et al. 1974. Determination of tripsin inhibitor activity on soy products: a collaborative analysis of na improved procedure. Cereal Chem., 51:376-382.

LIENER, I. E. 1994. Implications of antinutritional components in soybeans foods. Critical Reviews in Food Sci. and Nutr., 34:31-67.

LIU, K., MARKAKIS, P. 1989. An Improved colorimetric method for determining antitryptic activity in soybean products. Cereal Chem., 66:415-422.

NATIONAL RESEARCH COUNCIL - NRC. 1994. Nutrient requirements of poultry. 9.rev.ed. Washington: National Academy Press. 577p.

NITSAN, Z., NIR, I. 1977. A comparative study of the nutritional and physiological significance of raw and heated soybeans in chiks and goslings. Br. J. Nut., 37:81-91.

PUSZTAI, A., WATT,W.B., STEWART, J.C. 1991. A comprehensive scheme for the isolation of trypsin inhibitors and the aglutinin from soybean seeds. J. Agric. Food Chem. 39:862-866.

SNYDER, H.E., KWON, T.W.1987. Soybean utilization avibook New York. p.346.

WALKER, A.F. 1983. The estimation of protein quality. In. HUDSON, B.E.F. (Ed.) Developments in food protein, London and New York, v.2. 339p.

WILLIS, G.M., BAKER, D.H. 1980. Evaluation of turfgrass clippings as a dietary ingredient for the growing chick. Poult Sci., 59:404-411.

YEN, J.T., JENSEN, A.H., HYMOWITZ, T. et al. 1973. Utilization of different varieties of raw soybeans by male and female chicks. Poult. Sci., 52:1875-1882.

Recebido em: 08/02/00

Aceito em: 26/05/00 